Original Research Paper

\title{
Usability Validation of an Ergonomic Inward Directional Screwdriver for Enhanced Musculoskeletal Comfort
}

\author{
Poh Kiat Ng, Bing Sheng Choong and Kian Siong Jee \\ Faculty of Engineering and Technology, Multimedia University, Malacca, Malaysia
}

Article history

Received: 19-08-2016

Revised: $19-10-2016$

Accepted: 26-10-2016

Corresponding Author:

Poh Kiat Ng

Faculty of Engineering and

Technology, Multimedia

University, Malacca, Malaysia

Email: pkng@mmu.edu.my

\begin{abstract}
Previous studies suggested that the use of inward torque direction in hand-related manual activities not only increases the total normal force and torque capacity but also reduces grip force. This means lesser effort is required to perform the task, which prevents overexertion and hand injuries. Manual screwdrivers are the most common hand tools used in the industry and daily life. However, due to the difficulty users face when unfastening screws, it can also be a hand tool that potentially leads to the development of cumulative trauma disorders. In this study, 50 subjects participated in a psychophysical testing of an ergonomic inward directional screwdriver and a normal manual screwdriver. The comparative study involved the perceptions of grip, comfort and ease-of-twist for both normal and ergonomic manual screwdrivers. The data was analysed using the analysis of variance via Minitab 16. The results showed that grip, comfort and ease-of-twist are significantly affected by torque direction and ergonomics features. Further observations on participant justifications also suggested that participants rated the inward screwdriver as a better tool to be used compared to the normal screwdriver.
\end{abstract}

Keywords: Inward Direction, Screwdriver, Design, Ergonomics, Cumulative Trauma Disorders, Psychophysical Test

\section{Introduction}

In the advent of globalisation, the electronics industry has expanded to embrace various levels of challenges, complexities and opportunities in technological development, some of which include developments in CMOS circuits, semiconductors, low-noise amplifiers, radio frequency designs and $p$-channel MOSFET voltage multipliers (Bi et al., 2015; Yuan and Bi, 2015; Yuan et al., 2014). With the rise of electronics industrial research, manual tools such as screwdrivers would be essential for installations, fabrications, product design and maintenance.

Most manual screwdrivers were designed to operate with repetitive motion, which causes fatigue (Rohmert, 1973; Seo et al., 2008a; 2008b) and pain (Armstrong et al., 1993) to the musculoskeletal system. A forceful exertion can cause localised fatigue (Rohmert, 1973; Seo et al., 2007) and damage to the human body structure (Armstrong et al., 1993), leading to the development of Cumulative Trauma Disorders (CTDs) (Falck and Aarnio, 1983). Previous studies suggested that the use of inward torque direction increases the total normal force and torque capacity and reduces the grip force (Seo and Armstrong, 2008; 2011; Seo et al., 2007; 2008a; 2008b). This observation can be seen in the use of a normal manual screwdriver.

Manual screwdrivers are the most common hand tools used in the industry and daily life. However, due to the difficulty users face when unfastening screws, it can also be a hand tool that potentially leads to the development of cumulative trauma disorders. Even though there are many battery-powered screwdrivers in the market that can facilitate the act of unfastening screws, the battery's durability can pose as a key issue (Yuan and $\mathrm{Bi}, 2015$ ).

Hence, it would be of interest to look into the design innovation of a manual screwdriver. Based on a previous study conducted by $\mathrm{Ng}$ et al. (2016b), an ergonomic inward directional screwdriver was designed and developed to facilitate the unfastening of screws using the inward rotations of the hand. The current study aims to test the usability of this new screwdriver and prove that it enhances musculoskeletal comfort compared to a regular manual screwdriver. 


\section{Literature Review}

Previous studies mentioned that the comfort of a hand tool's handle is related to its functionality and physical interaction (Kuijt-Evers et al., 2004; KuijtEvers et al., 2007). The descriptors of functionality are task performance, function, ease of use, good force transmission and low grip force requirements (Gregor and Bojan, 2013; 2014; Kuijt-Evers et al., 2004; KuijtEvers et al., 2007; Wyoming, 2011). On the other hand, descriptors of physical interaction include the ability to fit in the hand, posture and pain or numbness in the hand and fingers (Kuijt-Evers et al., 2004; Kuijt-Evers et al., 2007). The above descriptors of comfort, functionality and physical interaction of the hand tool's handle can be improved in general by designing tools with proper diameters, shapes, materials and mechanisms.

\section{Relationship between Normal Force and Grip Force}

From the torque model proposed by Pheasant and O'Neill (1975), grip force is a resultant of normal forces of the fingertips, thumb and palm acting on the object surface. Hence, the increase of the resultant normal force increases the grip force (Seo et al., 2007; 2008a; 2008b), though the grip force recorded appears to be always lower than the total normal force (Seo et al., 2007; 2008a; 2008b). The findings by Seo et al. (2008a) show that grip force increases gradually while normal force increases, though the value of grip force may still depend on the counter balance of forces among the fingertips, thumb and palm.

It was found that the fingertips and thumb were high force contributors and major force components that acted on the object during grasping and turning activities. This finding was recorded by Seo et al. (2007) through a grip force distribution simulation. Under turning operation with inward or outward torque directions, researchers believed that more forces were distributed on the object by the fingertips for inward direction and by the thumb for outward direction (Seo et al., 2007; 2008b).

\section{The Effects of Torque Directions on Grip Force}

Studies by Seo et al. (2007) and Seo et al. (2008b) suggested that the relation between torque and grip force can be derived from the moment acting at the finger joint while grasping the object for a single torque. In theory, when inward torque direction is applied, the moment term of friction force becomes negative and results in the increase of normal force (Seo et al., 2007). Hence, inward torque generates higher normal force than outward torque.

In the study of Seo et al. (2007), inward torque direction was found to be able to increase the total normal force and maximum torque. It was found that the torque generation from the inward direction was $22 \%$ greater than that of the outward direction (Seo et al., 2007). Another study by Seo et al. (2008a) showed that more torque can be generated by using the inward direction, which was also $22 \%$ greater than using outward torque direction. Other related studies with different experimental manipulations also show that the inward torque direction produces greater torque than the outward torque direction (Morse et al., 2006; Ng et al., 2014a; Seo et al., 2008a).

Seo et al. (2007) found that grip force was lower when appliedinan inward direction as compared to outward direction for a handle diameter of $45.1 \mathrm{~mm}$. Similarly, other studies (Seo et al., 2008a; 2008b) also show that the grip force produced for inward directions was lesser compared to that of the outward torque direction for a submaximal torque, though higher torque was generated with the inward direction. When fastening screws for instance, the inward direction (pronated position) from a non-dominant hand would produce less force compared to the outward direction from a dominant hand, with approximately $8 \%$ differences in favour of inward directions (Strasser and Wang, 1998).However, the grip force for an inward maximal torque was greater than that of an outward maximal torque (Seo et al., 2008a; 2008b).

In short, performing torque-required tasks with an inward torque direction improves the torque capacity as compared to performing them with outward torque directions (Morse et al., 2006; Seo et al., 2007; 2008a; 2008b). The grip force increased with both torque directions, though the grip force for submaximal and maximal inward torques was respectively lower and higher than the grip force generated by outward torque. Besides that, the increase in handle friction (Seo et al., $2008 \mathrm{a} ; 2008 \mathrm{~b}$ ), increase in resistivity of handle shape towards finger phalanges segment (Kong et al., 2008) and an optimal(25-40mm) handle diameter (Edgren et al., 2004; Kong and Lowe, 2005a; Seo et al., 2007) also help in increasing the total normal force, resulting in a more stable and secure grip.

In conclusion, twisting with an inward torque direction increases the maximum torque capacity and total normal force. However, the required grip strength would be reduced with the inward direction though the torque capacity would remain the same. This would allow lesser effort required in twisting the object ( $\mathrm{Ng}$ et al., 2015).

For a previous study, an inward directional screwdriver was designed and developed to counter the outward rotations with inward rotations using the planetary gear system (Ng et al., 2016a; 2016b). This study intends to evaluate the performance of this ergonomic screwdriver and compare it with conventional manual screwdrivers.

\section{Materials and Method}

The method involved the test of participants' psychophysical perception in experiencing the difference between the ergonomic and non-ergonomic screwdriver. 
The ergonomic screwdriver was previously designed and developed in other studies ( $\mathrm{Ng}$ et al., 2016a; 2016b). The prototype was tested on a total of 50 volunteers (25 males and 25 females) whom all of which were manual labourers and technicians from a multinational company in Malacca, Malaysia.

The test was separated into two sections. Section A determined the effect of the ergonomic handle on the grip and comfort perceptions and section B determined the effect of torque direction and ergonomics features on the ease-of-twist and grip perceptions.

For the test in section A, all the participants were required to grasp the normal and ergonomic screwdrivers in their hand to experience the psychophysical effects based on grip and comfort perceptions. Figure 1 shows the handles used in this section. The ergonomic handle in the figure was shaped to conform with the user hand dimensions and equipped with rubber grips in order to promote a more secure grip and increased tactile sensation (Husain et al., 2013).

Section B involved an unfastening task for each of the screwdrivers in Figure 2. The input torque direction in this section depended on the screwdrivers' function in leveraging the torque direction to unfasten the screw. Users were evaluated based on their ease-of-twist perceptions when using the screwdrivers. In addition, the grip ability while twisting the screwdrivers was also evaluated in this section.
All the tests performed in section $\mathrm{B}$ required an upright standing posture. Figure 3 shows how the task was performed. The unfastening task performed by the participants was a general task, which included the unfastening of a desktop computer casing screw. The test required the participants to unfasten the screw with only an initial twist.

The testing scale used those tests was adapted from the study of Borg (1982). It was similar to the new category scale with ratio properties. The ratings of the scale in these tests ranged from 1 to 7 , where 1 is poor, 4 is neutral and 7 is strong.

\section{Analysis}

The analysis was done using the Analysis of Variance (ANOVA) to determine the significance of the effects of different inputs on the responses. A total number of four ANOVA analyses were performed with the use of the significance level of 0.05 .

Table 1 shows the grouping of the analyses and score coding. In section $\mathrm{A}, \mathrm{G}$ refers to grip, $\mathrm{C}$ refers to comfort, 1 refers to ergonomic handle and 2 refers to normal handle. In this section, the two analyses involved were of the AG and AC combinations. These two analyses were performed separately to determine the effect of ergonomics features on the grip ability and comfortability of the handle.

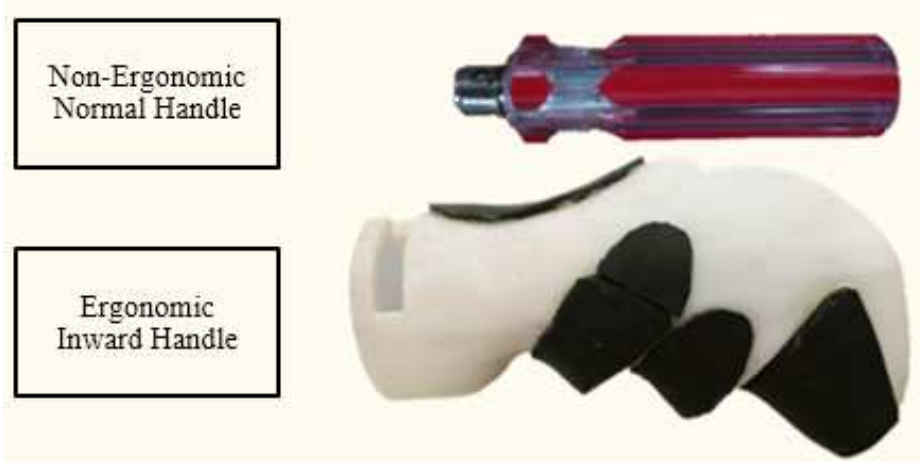

Fig. 1. The Handles Tested in Section A
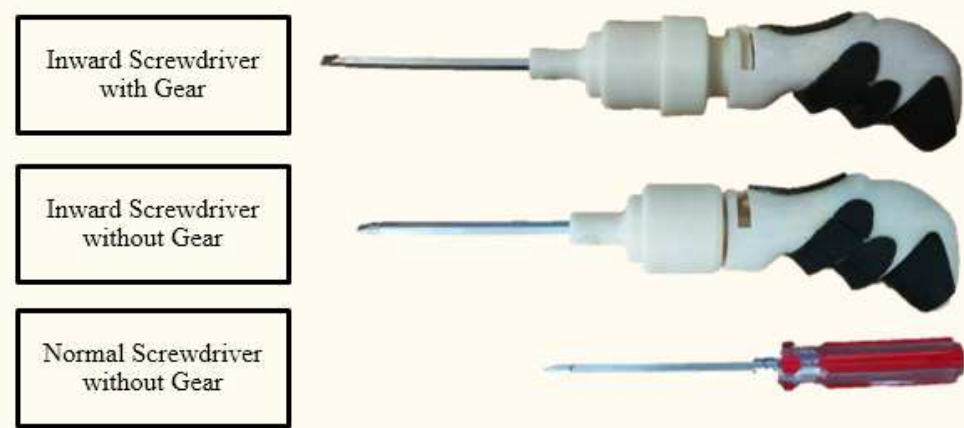

Fig. 2. The Screwdrivers Tested in Section B 
Table 1. The Grouping of Analysis and Scores Coding

\begin{tabular}{|c|c|c|c|c|c|c|c|c|c|c|}
\hline Analysis & 1 & & 2 & & 3 & & & 4 & & \\
\hline Sections & $\mathrm{A}$ & & $\mathrm{A}$ & & $\mathrm{B}$ & & & B & & \\
\hline Perception & Grip (G) & & Comf & & Grip & & & Ease- & t(E) & \\
\hline Screwdriver & 1 & 2 & 1 & 2 & 1 & 2 & 3 & 1 & 2 & 3 \\
\hline Code & AG1 & $\mathrm{AG} 2$ & $\mathrm{AC} 1$ & $\mathrm{AC} 2$ & BG1 & BG2 & BG3 & BE1 & BE2 & BE3 \\
\hline
\end{tabular}

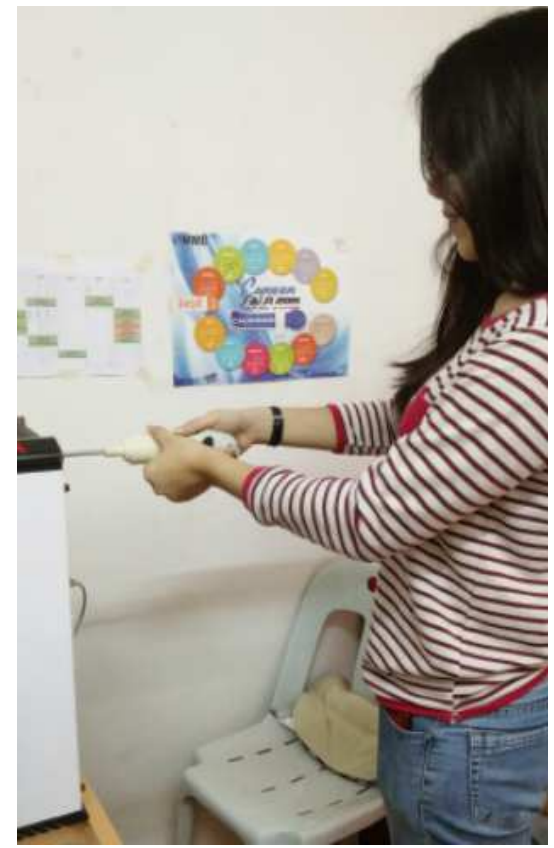

Fig. 3. Participant Performing the Test for Section B

In section $\mathrm{B}, \mathrm{G}$ refers to grip, $\mathrm{E}$ refers to ease-oftwist, 1 refers to inward screwdriver with gears, 2 refers to inward screwdriver without gears and 3 refers to normal screwdriver. For this section, the two major analyses involved were of the BG and BE combinations. Similarly, these two analyses were performed separately to determine if the torque direction, ergonomics features and gear mechanism significantly affect the grip ability and ease-of-twist of the screwdriver.

\section{Results and Discussion}

Table 2-9 shows the ANOVA results for the scores among different categories. Table 10 presents the justifications collected from the participants after the tests.

\section{Grip Ability of Handle}

On average, the participants rated the ergonomic handle with an average score of 5.6 (strong grip), whereas the normal handle was rated with an average score of 3.7 (neutral) (See Table 2). According to Table 3 , the effects of the ergonomic handle on the handle grip ability were found to be statistically significant $(p<0.05)$. Therefore, handle shape, diameter and surface material have significant effects on handle grip ability.

\section{Comfortability of Handle}

Based on Table 4, it was found that the participants rated the ergonomic handle with 'somewhat comfortable' (mean $=5.0$ ) and normal handle with 'somewhat uncomfortable' (mean = 3.0). The comfortability of the handle was significantly affected by the ergonomics features $(p<0.05)$ (Refer to Table 5). Hence, the handle which incorporates the ergonomics features shows a significant difference in terms of handle comfort ability.

\section{Grip Ability of Screwdriver}

According to Table 7, the effects of torque direction, ergonomics features and gear mechanism on grip ability are significant $(p<0.05)$. Participants rated a mean score close to 'strong grip' (mean $=5.8$ ) for theinward screwdriver with gears and a mean score close to 'somewhat more grip' (mean $=5.3$ ) for the inward screwdriver without gears (See Table 6). In addition, the normal screwdriver obtained a mean score close to 'somewhat less grip' (mean $=3.3$ ) from participants.

From the analysis, the effects of ergonomics features and gear mechanism on grip ability while twisting were significant. In addition, the ergonomic screwdriver without the gears also significantly affects the grip ability while twisting.

\section{Ease-of-Twist of Screwdriver}

Results show that participants rated a mean score slightly above 'easy' (mean $=6.3$ ) and a mean score slightly above 'somewhat easy' (mean $=5.4$ ) for the screwdriver with gears and without gears respectively (See Table 8). Lastly, a normal screwdriver in this section was rated by the participants with a mean score above 'somewhat uneasy' (mean = 3.2). Based on Table 9 , it was found that the effects of torque direction, ergonomics features and gear mechanism on the ease-oftwist were significant $(p<0.05)$.

\section{Justifications}

From justifications by participants from section $\mathrm{A}$ in Table 10, the handle of the normal screwdriver was too small and the surface finish had a low coefficient of friction. Most responses from the participants indicated that the normal screwdriver handle had poor grip ability and comfortability. Conversely, participants justified the ergonomics handle of the inward screwdriver to be fitting well in the hand and with a non-slip surface. 
Poh Kiat Ng et al. / American Journal of Applied Sciences 2016, 13 (11): 1076.1084 DOI: 10.3844/ajassp.2016.1076.1084

Table 2. The Descriptives Table (Mean) For AG Score

\begin{tabular}{|c|c|c|c|c|c|c|c|c|}
\hline & \multirow[b]{2}{*}{$\mathrm{N}$} & \multirow[b]{2}{*}{ Mean } & \multirow[b]{2}{*}{ Std. Dev } & \multirow[b]{2}{*}{ Std. Error } & \multicolumn{2}{|c|}{ 95\% Confidence Interval for Mean } & \multirow[b]{2}{*}{ Min } & \multirow[b]{2}{*}{ Max } \\
\hline & & & & & Lower Bound & Upper Bound & & \\
\hline AG1 & 50 & 5.6000 & 0.69921 & 0.22111 & 5.0998 & 6.1002 & 4.00 & 6.00 \\
\hline AG2 & 50 & 3.7000 & 0.82327 & 0.26034 & 3.1111 & 4.2889 & 3.00 & 5.00 \\
\hline Total & 100 & 4.6500 & 1.22582 & 0.27410 & 4.0763 & 5.2237 & 3.00 & 6.00 \\
\hline
\end{tabular}

Table 3. The ANOVA Summary Table for AG Score

\begin{tabular}{llllll}
\hline & Sum of Squares & df & Mean Square & F & Sig. $(p$-value $)$ \\
\hline Between Groups & 18.050 & 1 & 18.050 & 30.943 & $\mathbf{0 . 0 0 0}$ \\
Within Groups & 10.500 & 18 & 0.583 & & \\
Total & 28.550 & 19 & & & \\
\hline
\end{tabular}

Table 4. The Descriptives Table (Mean) For AC Score

\begin{tabular}{|c|c|c|c|c|c|c|c|c|}
\hline & \multirow[b]{2}{*}{$\mathrm{N}$} & \multirow[b]{2}{*}{ Mean } & \multirow[b]{2}{*}{ Std. Dev } & \multirow[b]{2}{*}{ Std. Error } & \multicolumn{2}{|c|}{ 95\% Confidence Interval for Mean } & \multirow[b]{2}{*}{ Min } & \multirow[b]{2}{*}{ Max } \\
\hline & & & & & Lower Bound & Upper Bound & & \\
\hline$\overline{\mathrm{AC} 1}$ & 50 & 5.0000 & 1.05409 & 0.33333 & 4.2459 & 5.7541 & 3.00 & 7.00 \\
\hline $\mathrm{AC} 2$ & 50 & 3.0000 & 1.24722 & 0.39441 & 2.1078 & 3.8922 & 2.00 & 5.00 \\
\hline Total & 100 & 4.0000 & 1.52177 & 0.34028 & 3.2878 & 4.7122 & 2.00 & 7.00 \\
\hline
\end{tabular}

Table 5. The ANOVA Summary Table for AC Score

\begin{tabular}{llllll}
\hline & Sum of Squares & df & Mean Square & F & Sig. $(p$-value $)$ \\
\hline Between Groups & 20.000 & 1 & 20.000 & 15.000 & $\mathbf{0 . 0 0 1}$ \\
Within Groups & 24.000 & 18 & 1.333 & & \\
Total & 44.000 & 19 & & & \\
\hline
\end{tabular}

Table 6. The Descriptives Table (Mean) For BG Score

\begin{tabular}{|c|c|c|c|c|c|c|c|c|}
\hline & \multirow[b]{2}{*}{$\mathrm{N}$} & \multirow[b]{2}{*}{ Mean } & \multirow[b]{2}{*}{ Std. Dev } & \multirow[b]{2}{*}{ Std. Error } & \multicolumn{2}{|c|}{$95 \%$ Confidence Interval for Mean } & \multirow[b]{2}{*}{ Min } & \multirow[b]{2}{*}{ Max } \\
\hline & & & & & Lower Bound & Upper Bound & & \\
\hline BG1 & 50 & 5.8000 & 0.78881 & 0.24944 & 5.2357 & 6.3643 & 5.00 & 7.00 \\
\hline BG2 & 50 & 5.3000 & 0.48305 & 0.15275 & 4.9544 & 5.6456 & 5.00 & 6.00 \\
\hline BG3 & 50 & 3.3000 & 0.82327 & 0.26034 & 2.7111 & 3.8889 & 2.00 & 5.00 \\
\hline Total & 150 & 4.8000 & 1.29721 & 0.23684 & 4.3156 & 5.2844 & 2.00 & 7.00 \\
\hline
\end{tabular}

Table 7. The ANOVA Summary Table for BG Score

\begin{tabular}{llllll}
\hline & Sum of Squares & df & Mean Square & F & Sig. $(p$-value $)$ \\
\hline Between Groups & 35.000 & 2 & 17.500 & 34.239 & $\mathbf{0 . 0 0 0}$ \\
Within Groups & 13.800 & 27 & 0.511 & & \\
Total & 48.800 & 29 & & & \\
\hline
\end{tabular}

Table 8. The Descriptives Table (Mean) For BE Score

\begin{tabular}{|c|c|c|c|c|c|c|c|c|}
\hline & \multirow[b]{2}{*}{$\mathrm{N}$} & \multirow[b]{2}{*}{ Mean } & \multirow[b]{2}{*}{ Std. Dev } & \multirow[b]{2}{*}{ Std. Error } & \multicolumn{2}{|c|}{$95 \%$ Confidence Interval for Mean } & \multirow[b]{2}{*}{ Min } & \multirow[b]{2}{*}{ Max } \\
\hline & & & & & Lower Bound & Upper Bound & & \\
\hline$\overline{\mathrm{BE} 1}$ & 50 & 6.3000 & 0.82327 & 0.26034 & 5.7111 & 6.8889 & 5.00 & 7.00 \\
\hline BE2 & 50 & 5.4000 & 0.96609 & 0.30551 & 4.7089 & 6.0911 & 4.00 & 7.00 \\
\hline BE3 & 50 & 3.2000 & 1.13529 & 0.35901 & 2.3879 & 4.0121 & 2.00 & 5.00 \\
\hline Total & 150 & 4.9667 & 1.62912 & 0.29743 & 4.3583 & 5.5750 & 2.00 & 7.00 \\
\hline
\end{tabular}

Table 9. The ANOVA Summary Table for BE Score

\begin{tabular}{llllll}
\hline & Sum of Squares & df & Mean Square & F & Sig. $(p$-value $)$ \\
\hline Between Groups & 50.867 & 2 & 25.433 & 26.310 & $\mathbf{0 . 0 0 0}$ \\
Within Groups & 26.100 & 27 & 0.967 & & \\
Total & 76.967 & 29 & & & \\
\hline
\end{tabular}


Table 10. Participants Justifications

\begin{tabular}{|c|c|c|c|c|}
\hline Section & Perception & Screwdriver & Rating & Justifications \\
\hline$\overline{\mathrm{A}}$ & Grip & Inward (Handle) & 6 & No slips \\
\hline A & Comfort & Normal (Handle) & 2 & Too small \\
\hline B & Ease of Twist & Inward (Gear) & 6 & More comfortable to be twisted in this direction \\
\hline $\mathrm{B}$ & Ease of Twist & Normal (No Gears) & 2 & Requires more effort \\
\hline A & Grip & Inward (Handle) & 6 & Strong grip, high frictional surface \\
\hline A & Comfort & Normal (Handle) & 2 & Size too small, low frictional surface \\
\hline A & Grip & Inward (Handle) & 6 & Fits well in the hand \\
\hline A & Comfort & Normal (Handle) & 2 & Too small, hard plastic surface \\
\hline B & Grip & Inward (Gears) & 6 & Non-slip surface \\
\hline B & Grip & Inward (No Gears) & 6 & Non-slip surface \\
\hline B & Grip & Normal (No Gears) & 2 & Slips during twisting, difficult to secure in the hand \\
\hline A & Comfort & Normal (Handle) & 2 & Too small \\
\hline B & Grip & Inward (Gears) & 6 & Comfortable and able to be held firmly in hand \\
\hline B & Ease of Twist & Inward (Gears) & 6 & Requires less effort for twisting \\
\hline $\mathrm{B}$ & Grip & Inward (No Gears) & 6 & Sufficient grip \\
\hline B & Ease of Twist & Inward (No Gears) & 6 & Requires less effort for twisting \\
\hline $\mathrm{B}$ & Grip & Inward (Gears) & 7 & Gears and ergonomic grip provide more comfort when twisting \\
\hline $\mathrm{B}$ & Ease of Twist & Inward (Gears) & 7 & Gears and ergonomic grip improves ease of twist \\
\hline A & Grip & Inward (Handle) & 6 & Fits well in the hand \\
\hline $\mathrm{B}$ & Grip & Inward (No Gears) & 6 & Fits well in the hand \\
\hline A & Grip & Inward (Handle) & 6 & Fits well in the hand \\
\hline $\mathrm{B}$ & Grip & Inward (Gears) & 7 & Non-slip surface \\
\hline A & Grip & Inward (Handle) & 6 & Not easy to slip off fingers \\
\hline A & Comfort & Inward (Handle) & 7 & Fits well within fingers and palm \\
\hline $\mathrm{B}$ & Ease of Twist & Inward (No Gears) & 6 & Easily twisted \\
\hline $\mathrm{B}$ & Ease of Twist & Normal (No Gears) & 2 & More effort is applied when twisting \\
\hline $\mathrm{B}$ & Grip & Inward (Gears) & 6 & Seem to have a more secure grip when twisting \\
\hline A & Grip & Inward (Handle) & 6 & Fingers and palm secured in the grip, less effort utilised \\
\hline A & Comfort & Inward (Handle) & 6 & Shape of the handle follows contour of hands \\
\hline $\mathrm{B}$ & Grip & Inward (Gears) & 6 & Effortless grip while twisting \\
\hline $\mathrm{B}$ & Ease of Twist & Inward (Gears) & 7 & Very easy to twist \\
\hline A & Comfort & Normal (Handle) & 2 & Fits well in the hand \\
\hline B & Ease of Twist & Inward (No Gears) & 6 & Less effort used when gripping \\
\hline B & Ease of Twist & Inward (Gears) & 7 & Requires less effort for twisting \\
\hline
\end{tabular}

Thus, participants rated this ergonomic handle as a comfortable handle that provides a secure grip.

In section $\mathrm{B}$, participants justified that the inward screwdriver with gears required lesser effort to unfasten screws as compared to the normal screwdriver. In addition, the participants also justified the same effect for the inward screwdriver with no gears as compared with a normal screwdriver.

\section{Effect of Ergonomics Features on Handle Grip}

From the first analysis in section A, the grip was significantly affected by the ergonomics features of the handle $(p<0.05)$ (Table 2 and 3$)$. The combination of ergonomics features (optimum diameter, elliptical shape and rubber material) on this handle improved thegrip.

Participants rated the ergonomic handle $($ mean $=5.6)$ better than the normal handle (mean $=3.7$ ) and justified that it comfortably fits in the hand with a rubber non-slip surface. The handle grip is improved by the optimum handle diameter in a way where it is easier to be secured in the hand and increases voluntary force applications. It is supported by other studies, where an optimal handle diameter increases the grip force and total normal force (Edgren et al., 2004; Kong and Lowe, 2005b; Mastalerz et al., 2009; Seo and Armstrong, 2008). At the same time, the secureness of the handle in the hand can be explained as the optimal handle diameter allowed the thumb and fingertips to work together against the palm, resulting in a greater reaction force (Seo and Armstrong, 2008). In addition, the grip force decreases along with the increase of the handle diameter beyond the optimal diameter (Edgren et al., 2004; Kong and Lowe, 2005b; Mastalerz et al., 2009; Seo and Armstrong, 2008).

The handle has ergonomics features with an elliptic shape and hand-accommodating grooves, where some of the participants justified that it provided a more secure fit for the hand. The importance of an ergonomic handle shape was explained by Kong et al. (2008), Seo and Armstrong (2011) and Shih and Wang (1996), who concurred that a circular handle shape is unable to provide sufficient contact between fingers phalanges sectors and therefore would produce a lower total normal force as compared to an elliptic shape. Moreover, a 
larger normal force generation would lead to a larger frictional force and this notion prevents hand slippages and promotes a secure grip.

Being a soft material, rubber has a considerably higher coefficient of friction as compared to hard plastic and metal. The use of a material with a higher coefficient of friction for the handle tends to decrease the amount of grip force and total normal force, though it does not decrease the amount of torque generated (Seo and Armstrong, 2008; 2008a; 2008b). A higher coefficient of friction would also mean that lower normal and grip forces are required to achieve the same amount of friction force for torque generation purposes, which would result in a lower effort required to perform the task.

\section{Effect of Ergonomics Features on Handle Comfort}

The continued analysis showed that the ergonomics features significantly affected the comfortability of the handle $(p<0.05)$ (Table 4 and 5). A handle with a diameter that can accommodates the handgrip would improve comfort because the contact area between the hand and handle increases. This finding is similar to the findings by Gregor and Bojan (2013), Gregor and Bojan (2014) and Seo and Armstrong (2008), who agree that when an optimum handle diameteris used, it increases the contact area and decreases the contact pressure on the hand, leading to a reduction in discomfort. A smaller handle diameter would in turnresult in an awkward gripping posture and increase the fatigue rate.

The analysis also found that participants rated the elliptic shaped handle (ergonomic handle, mean $=5$ ) with a higher score than the hexagonal-shaped handle (normal handle, mean $=3$ ). The comfortability of the elliptic handle shape was tested by Kong et al. (2008), who found that it was the most comfortable shape among the other tested shapes. Seo and Armstrong (2011) and Gregor and Bojan (2014) also suggested that elliptic and anatomical shaped handles fit more comfortably in the hands. Hence, the handle with a more handaccommodating shape can help improve comfortability.

For surface material, a softer material like rubber can increase the comfortability of the handle by reducing the peak pressure on the hands (Kuijt-Evers et al., 2004; Kuijt-Evers et al., 2007). By increasing the coefficient of friction, lower effort would be required to grip the handle, thus reducing the risks of overexertion and discomfort.

\section{Effect of Torque Direction, Ergonomics Features and Gear Mechanism on Screwdriver Grip Ability}

The first analysis in section B shows that torque direction, ergonomics features and gear mechanism significantly affects the grip ability of the screwdriver $(p<0.05)$ (Table 6 and 7). From the results rated by participants, the inward screwdriver (mean $=5.8$ ) provided a more secure grip as compared to the normal screwdriver $($ mean $=3.3)$. This means that the torque direction, ergonomics features and gear mechanism for the inward screwdriver improved grip ability. The evidences are found in previous studies, where applying the inward torque resulted in lower grip force and higher total normal force as compared to outward torque (Seo et al., 2007; 2008a; 2008b). This was because twisting with an inward direction allowed a larger concentration of forces to be generated by the four phalanges (Seo et al., 2007). Therefore, applying torque in this direction allowed users to maintain the capacity of torque while reducing the effort to grip the screwdriver. Conversely, when twisting with an outward direction, the four fingertips tend to lose their grip on the surface due to a decrease of total normal force ( $\mathrm{Ng}$ et al., 2014b). Hence, people would tend to apply more effort to securely grip the handle in the outward direction.

The combination of ergonomics features (handle diameter, shape and surface material) improved the grip while twisting. The participants justified that the ergonomic handle (mean $=5.8$ and 5.3) comfortably fit in the hand with no slippages while twisting. All of this was due to the optimum handle diameter, elliptic shape and rubber surface material. The optimum handle diameter and elliptic shaped handle disallowed the hand and wrist position to assume an awkward posture.

The gear mechanism with a gear ratio of 2 also improved the grip while twisting because less grip force was required to generate thesame amount of output torque. The reduced grip force can avoid overexertion and slippages between handle and hands.

\section{Effect of Torque Direction, Ergonomics Features and Gear Mechanism on Ease-of-Twist}

The final analysis shows that the ease-of-twist of the screwdriver was significantly affected by the torque direction, ergonomics features and gear mechanism $(p<$ 0.05) (Table 8 and 9). Participants justified that the inward screwdriver with gears $($ mean $=6.3$ ) was easier to twist compared to the one without gears. Similar results were found in previous studies, where applying inward torque generated a higher torque capacity, which means that the object was easier to twist (Seo et al., 2007; $2008 \mathrm{a} ; 2008 \mathrm{~b}$ ). Therefore, the desired output torque with reduced grip force can be achieved using this direction since more normal forces are generated from the phalanges in this twisting direction, resulting in a lower voluntary grip force.

For ergonomics features, the optimum handle diameter improved the surface contact area, therefore, increasing the total normal force. This was explained by previous researchers, who agreed that with an optimum handle diameter, the fingertips and thumb can exert force together to create a greater reaction force on the palm, resulting in a greater total normal force (Seo and Armstrong, 2008; Seo et al., 2007). 
The elliptic shape offers a greater moment arm, which generates a larger amount of torque. This was specifically studied by Seo and Armstrong (2011), who found that the 4 major finger forces exerted on the longest moment arm position resulted in greater torque capacity.

Furthermore, the increases in the coefficient of friction resulted in increased torque capacity because a larger total normal force can be produced. Previous studies concluded that the increase in the coefficient of friction would increase the maximum total normal force though a lower normal force would be required for the same amount of desired output torque (Seo et al., 2008a; 2008b).

Lastly, the inward screwdriver with gear mechanism (mean $=6.3$ ) was easier to twist than the inward screwdriver without gears (mean $=5.4)$ and the normal screwdriver without gears $($ mean $=3.2)$. This was because the gear ratio of this gear train was 2 , thus implying that the input torque was amplified. Hence, lesser effort was required in achieving the same amount of torque capacity.

Although the usability of this screwdriver was verified, much work may still be required (design improvements, final product fabrication and experimentations with physical measurements). However, similar to other studies, this study may serve as a guideline for other researchers and designers, as it often happens that the performance of the final design deviates from the original settings (Bi et al., 2015). In future, perhaps electromyography could be used as a means to collect the intensity measurements of muscle exertions in order to further verify the usability of this screwdriver (Strasser et al., 2004).

\section{Conclusion and Future Recommendations}

The grip force required was lesser for the inward torque direction as compared to the outward torque direction, though a higher total normal force was generated in the inward torque direction. The results and analyses from this study verified that participants rated the inward screwdriver with a better gripability and easeof-twist compared to the normal screwdriver.

Through the test results, considering an inward torque direction with ergonomics features can improve the grip ability, comfortability and output torque. In future, more experimental methods involving biomechanical instruments should be introduced to measure the results in terms of physical quantities for a better interpretation of the results.

\section{Acknowledgement}

The authors would like to acknowledge the Faculty of Engineering and Technology as well as the Research Management Centre of Multimedia University for the tremendous support given in conducting this research. The data presented, statements made and views expressed are solely the responsibility of the authors.

\section{Funding Information}

This research was supported by the Faculty of Engineering and Technology as well as the Research Management Centre of Multimedia University Malaysia.

\section{Author's Contributions}

Poh Kiat Ng: Dr. Ng initiated the idea and concept of the inward directional screwdriver. He also designed the experiment and planned out the test protocol. Most of the statistical analyses were also done by him. The literature studies and discussions were also done by him.

Bing Sheng Choong: Mr. Choong was involved in a large portion of the literature review write-up. He was also responsible for conducting the experiments and collecting the data. The design of the inward directional screwdriver was predominantly produced by him.

Kian Siong Jee: Mr. Jee was primarily involved in the write-up of the methodology. He also aided Dr. $\mathrm{Ng}$ by contributing some of his ideas and observations in the discussion and conclusion sections of this paper.

\section{Ethics}

This article is original and contains unpublished material. The corresponding author confirms that all the other authors have read and approved the manuscript. Hence, no ethical issues are involved.

\section{References}

Armstrong, T., J. Buckle, P. Fine, L.J. Hagberg and M. Jonsson et al., 1993. A conceptual model for workrelated neck and upper-limb musculoskeletal disorders. Scandinavian J. Work, Environment Health, 19: 73-84.

Bi, Y., J.S. Yuan and Y. Jin, 2015. Beyond the interconnections: Split manufacturing in Rf designs. Electronics, 4: 541-564.

Borg, G.A.V., 1982. Psychophysical bases of perceived exertion. Medicine Science Sports Exercise, 14: 377-381.

Edgren, C.S., R.G. Radwin and C.B. Irwin, 2004 .Grip force vectors for varying handle diameters and hand sizes. Human Factors, 46: 244-251. DOI: $10.1518 /$ hfes.46.2.244.37337

Falck, B. and P. Aarnio, 1983. Left-sided carpal tunnel syndrome in butchers. Scandinavian J. Work Environment Health, 9: 291-297.

Gregor, H. and D. Bojan, 2013. Tool-handle design based on a digital human hand model. Int. J. Industrial Ergonomics, 43: 288-295. DOI: $10.1016 /$ j.ergon.2013.05.002 
Gregor, H. and D. Bojan, 2014. Comparison of subjective comfort ratings between anatomically shaped and cylindrical handles. Applied Ergonomics, 45: 943-954. DOI: $10.1016 /$ j.apergo.2013.11.011

Husain, A., A.A. Khan and F. Hasan, 2013. Ergonomic evaluation of effects of handle shape and task orientation on human performance in screw driving task. Int. J. Advancements Technology, 4: 105-114.

Kong, Y.K. and B.D. Lowe, 2005a. Evaluation of handle diameters and orientations in a maximum torque task. Int. J. Industrial Ergonomics, 35: 1073-1084. DOI: 10.1016/j.ergon.2005.04.009

Kong, Y.K. and B.D. Lowe, 2005b. Optimal cylindrical handle diameter for grip force tasks. In. J. Industrial Ergonomics, 35: 495-507. DOI: 10.1016/j.ergon.2004.11.003

Kong, Y.K., B.D. Lowe, S.J. Lee and E.F. Krieg, 2008. Evaluation of Handle Shapes for Screwdriving. Applied Ergonomics, 39: 191-198. DOI: 10.1016/j.apergo.2007.05.003

Kuijt-Evers, L.F.M., L. Groenesteijn, M.P.D. Looze and P. Vink, 2004. Identifying factors of comfort in using hand tools. Applied Ergonomics, 35: 453-458. DOI: 10.1016/j.apergo.2004.04.001

Kuijt-Evers, L.F.M., P. Vink and M.P.D. Looze, 2007. Comfort predictors for different kinds of hand tools: Differences and similarities. Int. J. Industrial Ergonomics, 37: 73-84. DOI: $10.1016 /$ j.ergon.2006.09.019

Mastalerz, A., E. Nowak, I. Palczewska and E. Kalka, 2009. Maximal grip force during holding a cylindrical handle with different diameters. Human Movement, 10: 26-30. DOI: $10.2478 / \mathrm{v} 10038-009-0001-7$

Morse, J.L., M.C. Jung, G.R. Bashford and M.S. Hallbeck, 2006. Maximal dynamic grip force and wrist torque: The effects of gender, exertion direction, angular velocity and wrist angle. Applied Ergonomics, 37: 737-742.

DOI: $10.1016 /$ j.apergo.2005.11.008

Ng, P.K., A. Saptari and J.A. Yeow, 2014b. Synthesising the roles of torque and sensation in pinch force: A framework. Theoretical Issues Ergonomics Science, 15: 193-204.

Ng, P.K., A. Saptari, K.S. Jee and Y.H. Tan, 2015. Torque direction and its influence on pinch force in loaded and unloaded conditions. Australian J. Basic Applied Sciences, 9: 74-79.

Ng, P.K., K.S. Jee and B.S. Choong, 2016a. Design innovation of a manual screwdriver using the inventive principles of TRIZ. Middle-East J. Scientific Res., 24: 372-378.

Ng, P.K., K.S. Jee and B.S. Choong, 2016b. Designing an ergonomic inward directional screwdriver using TRIZ inventive principles. Proceedings of the International Conference on Applied and Engineering Physics (AEP' 16), Penang, Malaysia.
Ng, P.K., K.X. Chai, S.L. Leh, M.C. Bee and Q.H. Boon et al., 2014a. Applying clockwise and counterclockwise torque direction in pinch grips: a descriptive study. Applied Mechanics and Materials, 465-466: 1170-1174.

Pheasant, S. and D. O'Neill, 1975. Performance in gripping and turning-a study in hand/handle effectiveness. Applied Ergonomics, 6: 205-208.

Rohmert, W., 1973. Problems in determining rest allowances. Applied Ergonomics, 4: 91-95. DOI: 10.1016/0003-6870(73)90082-3

Seo, N.J. and T.J. Armstrong, 2008. Investigation of grip force, normal force, contact area, hand size and handle size for cylindrical handles. Human Factors, 50: 734-744.

Seo, N.J. and T.J. Armstrong, 2011. Effect of elliptic handle shape on grasping strategies, grip force distribution and twisting ability. Ergonomics, 54: 961-970.

Seo, N.J., T.J. Armstrong, D.B. Chaffin and J.A. AshtonMiller, 2008a. The effect of handle friction and inward or outward torque on maximum axial push force. Human Factors, 50: 227-236.

Seo, N.J., T.J. Armstrong, D.B. Chaffin and J.A. AshtonMiller, 2008b. Inward torque and high-friction handles can reduce required muscle efforts for torque generation. Human Factors, 50: 37-48.

Seo, N.J., T.J. Armstrong, J.A. Ashton-Miller and D.B. Chaffin, 2007. The effect of torque direction and cylindrical handle diameter on the coupling between the hand and a cylindrical handle. J. Biomechanics, 40: 3236-3243.

Shih, Y.C. and M.J.J. Wang, 1996. Hand/tool interface effects on human torque capacity. Int. J. Industrial Ergonomics, 18: 205-213.

Strasser, H. and B. Wang, 1998. Screwdriver torque strength and physiological cost of muscles dependent on hand preference and direction of rotation. Occupational Ergonomics, 1: 13-22.

Strasser, H., K. Kluth and E. Keller, 2004. A computerbased system for the use of electromyographic methods for the measurement of physiological costs associated with operating hand-held tools and computer input devices. Occupational Ergonomics, 4: 73-87.

Wyoming, 2011. What to look for when selecting or modifying hand tools to provide a better fit for the user.

Yuan, J.S. and Y. Bi, 2015. Process and temperature robust voltage multiplier design for $\mathrm{Rf}$ energy harvesting. Microelectronics Reliability, 55: 107-113.

Yuan, J.S., Y. Xu, S.D. Yen, Y. Bi and G.W. Hwang, 2014. Hot carrier injection stress effect on a $65 \mathrm{Nm}$ Lna at 70 Ghz. IEEE Trans. Device Materials Reliability, 14: 931-934. 